\title{
Excretion of pyridinium crosslinks correlates with disease activity and appendicular bone loss in early rheumatoid arthritis
}

\author{
Andrew K S Gough, Nicola F A Peel, Richard Eastell, Roger L Holder, John Lilley, \\ Paul Emery
}

\begin{abstract}
Objective-To establish if urinary excretion rates of the collagen crosslinks pyridinoline and deoxypyridinoline, which are known to be elevated in established rheumatoid arthritis (RA), are useful markers of bone loss in this disease.

Methods-Eight hour urine collections on all patients and 52 controls were performed, and the rates of pyridinoline and deoxypyridinoline excretion were measured. Bone mineral density (BMD), by dual energy $x$-ray absorption, and full laboratory and clinical assessments were performed.

Results-The rates of excretion of pyridinoline and deoxypyridinoline were significantly increased in patients compared with controls $(p<0.001)$. Pyridinoline excretion was associated with increased disease activity (ESR/CRP) but not disability (HAQ score/Functional Grade), and correlated with BMD loss at the femoral neck $(p<0.01)$.

Conclusion-The excretion of collagen crosslinks may be useful as markers of bone and cartilage turnover in patients with RA.
\end{abstract}

The Department of

Rheumatology and

School of Mathematics

and Statistics,

University of

Birmingham,

United Kingdom

A K S Gough

R L Holder

P Emery

Department of Human Metabolism and

Clinical Biochemistry,

University of Sheffield,

United Kingdom

NF A Peel

$\mathrm{R}$ Eastell

Department of Nuclear Medicine, Queen

Elizabeth Hospital,

Birmingham, United

Kingdom

J Lilley

Correspondence to:

Dr Emery,

Dr Emery,

Department of

Rheumatology, University Birmingham, B15
United Kingdom.

United Kingdom.

10 August 1993

\section{(Ann Rheum Dis 1994; 53: 14-17)}

Secondary osteoporosis is a feature of rheumatoid arthritis (RA). ${ }^{1}$ The earliest manifestation in RA is juxta articular osteoporosis which can occur within weeks of disease onset ${ }^{2}$ and is a characteristic feature of the disease. ${ }^{3}$ Generalised osteoporosis is also a well documented feature of late disease, although its primary causes are poorly understood. ${ }^{4-9}$ The importance of this osteoporosis is reflected by the increased risk of fractures in chronic $\mathrm{RA}^{10-12}$ and the significant morbidity and mortality associated with femoral neck fractures when they occur. ${ }^{13}$ As there is evidence suggesting that bone loss in patients with RA occurs rapidly and early in their disease, ${ }^{14-16}$ it is desirable to study patients as soon as possible. Additionally, by doing so, any association between disease activity and bone loss can be studied, uncomplicated by the confounding variables of immobility and corticosteroid use. Dual energy $x$ ray absorptiometry (DXA) has made measurement of the skeleton quick and accurate using a low dose of radiation. ${ }^{17}$

Despite the many advantages of DXA there is still a need for a sensitive and specific marker which is able to identify patients who are 'fast bone losers' and to provide rapid indication of any response to therapy. Measurement of the urinary excretion of the collagen crosslinks pyridinoline and deoxypyridinoline has been proposed as such. ${ }^{18-20}$ Deoxypyridinoline is bone specific, being found in type I collagen only. ${ }^{21}$ By contrast pyridinoline is found both in skeletal and vascular connective tissue, but quantitatively is the major crosslinking compound in bone. Following mature collagen degradation, these crosslinks are released in free of peptide forms and are excreted unchanged in urine, where they can be accurately quantified using HPLC. ${ }^{22}{ }^{23}$ Unlike hydroxyproline, they are not absorbed from the gut, ${ }^{22}$ and there is no interference by noncollagenous proteins such as Clq. Urinary excretion rates have been correlated with bone resorption in established osteoporosis, as assessed by radiostrontium kinetics. ${ }^{24}$ This is the first attempt to use the pyridinium crosslinks to predict axial and appendicular bone loss in a longitudinal prospective study of patients with early RA.

\section{Patients and methods}

Sixty two patients were recruited consecutively from the Early Inflammatory Arthritis clinic at Selly Oak Hospital, Birmingham. Patients had to fulfil 1987ARA criteria for $\mathrm{RA}^{3}$ and to have received no corticosteroids or disease modifying drugs (DMARDs). All received written information before giving their consent.

Patients were assessed by clinical and laboratory means at entry, three, six and 12 months, by the same clinician and metrologist. This included the completion of the health assessment questionnaire (HAQ) ${ }^{25}$ recording of Functional Grade (FG) ${ }^{26}$ and measurement of erythrocyte sedimentation rate (ESR) and C reactive protein (CRP). During the year between scans all DMARD use and steroid administration by any route were recorded. The latter was expressed as mg equivalents of prednisolone per day given over the 12 month period. No intra-articular steroids were allowed in the two months before assessments. Patients also completed a questionnaire detailing calcium intake, smoking habits and 
Table $1 A$ Patients' demographic details at entry

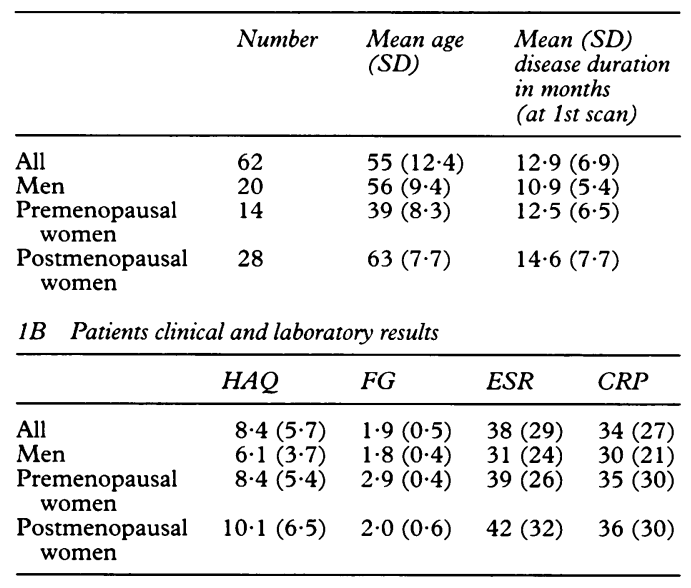

alcohol consumption in unit per day. Details on HRT use, menopausal status and number of postmenopausal years were noted in female patients, where appropriate.

Bone densitometry was performed at presentation using a Lunar DPX densitometer (Lunar Radiation Corp, Maddison, Wisconsin, USA) with version 3.1 of the software. This machine was calibrated daily using a quality assurance phantom. In vivo precision for the lumbar spine was $0.8 \pm 0.25 \%$ and for the femoral neck was $1.6 \pm 0.8 \%$ on normal volunteers. ${ }^{17}$ Radiation dose at the skin was low, in the order of 10-40 m SV. Measurements for each patient were recorded as total bone mineral density of L2-L4 inclusive and as an average of both femoral necks. Scans were repeated at one year (mean 12.8 months, range $11-15)$, and the percentage change, corrected to 12 months, calculated for each patient at both sites.

An eight hour urine collection was performed by all patients in the first three months of the year of follow up and by 56 healthy controls with no arthritis. ${ }^{27}$ All specimens were collected in plain bottles, timed between $7.30 \mathrm{am}$ and $3.30 \mathrm{pm}$. The volume was recorded and a $20 \mathrm{ml}$ aliquot stored at $-20^{\circ} \mathrm{C}$ until analysis for crosslinks,

Table $2 A$ Urinary pyridinoline excretion rates in patients and controls, mean (SD)

\begin{tabular}{llllll}
\hline & Controls & \multicolumn{5}{c}{ Patients } \\
\cline { 2 - 6 } & Number & $\begin{array}{l}\text { Pyridinoline } \\
\text { nmol8 hour }\end{array}$ & Number & $\begin{array}{l}\text { Pyridinoline } \\
\text { nmol/8 hour }\end{array}$ & p Value \\
\hline All & 56 & $153(84)$ & 62 & $254(116)$ & $<0.001$ \\
Men & 25 & $150(65)$ & 20 & $251(106)$ & 0.004 \\
$\begin{array}{l}\text { Premenopausal } \\
\quad \text { women }\end{array}$ & 16 & $124(59)$ & 14 & $218(84)$ & 0.002 \\
$\begin{array}{l}\text { Postmenopausal } \\
\text { women }\end{array}$ & 15 & $190(120)$ & 28 & $275(137)$ & $0.06(\mathrm{NS})$ \\
& & & & &
\end{tabular}

$2 B$ Urinary deoxypyridinoline excretion rates in patients and controls, mean (SD)

\begin{tabular}{llllll}
\hline & Controls & \multicolumn{5}{c}{ Patients } \\
\cline { 2 - 6 } & Number & $\begin{array}{l}\text { Deoxypyridinoline } \\
\text { nmol/8hour }\end{array}$ & Number & $\begin{array}{l}\text { Deoxypyridinoline } \\
\text { nmol/8 hour }\end{array}$ & p Value \\
\hline All & 56 & $34(19)$ & 62 & $64(35)$ & $<0 \cdot 001$ \\
Men & 25 & $31(16)$ & 20 & $58(28)$ & $0 \cdot 005$ \\
$\begin{array}{l}\text { Premenopausal } \\
\quad \text { women }\end{array}$ & 16 & $50(14)$ & 14 & $61(50)$ & 0.006 (NS) \\
$\begin{array}{l}\text { Postmenopausal } \\
\quad \text { women }\end{array}$ & 15 & $42(26)$ & 28 & $74(28)$ & 0.004 \\
\hline
\end{tabular}

NS $=$ Not significant. using the method Colwell et al, ${ }^{22}$ a modification of Black et al..$^{23}$ Briefly, $250 \mathrm{ml}$ aliquots of urine were hydrolysed at $110^{\circ} \mathrm{C}$ for 18 hours in equal volumes of 6 molar hydrochloric acid. This converts the peptide bound crosslinks to their free forms. The resulting hydrolysates were fractionated by CFI cellulose column chromatography to remove interfering fluorescent compounds. The crosslinks were separated and quantified by reverse-phase HPLC with fluorescent spectroscopy using heptafluorobutyric acid as the ion pairing agent. Duplicate samples were analysed for each patient and from this eight hour urinary excretion rates were calculated with values expressed in nmol per eight hours. The intra assay variation was $<10 \%$ for pyridinoline and $<15 \%$ for deoxypyridinoline.

$T$ tests and product moment correlation coefficients were used to examine the association between pairs of factors, but as several questionnaire and qualitative factors could have potentially influenced a patient's $\mathrm{BMD}$, analysis of covariance was finally used to examine the relative significance of each factor. Where necessary, a backward elimination of the least significant factors was performed to arrive at the collection of factors having a significant effect on bone loss.

\section{Results}

The demographic and descriptive details of the 62 patients studied are shown in table 1a. The mean HAQ, FG, ESR and CRP was calculated for each patient from their visits over the 12 month period. The group means of these are shown in table $1 \mathrm{~b}$. These values show that there was little difference in disease activity or functional status between these groups of patients with early RA.

Urinary eight hour crosslink excretion rates were significantly increased in patients with early RA in all patient groups, except postmenopausal women for pyridinoline and premenopausal women for deoxypyridinoline (table 2a, b). Comparing crosslink excretion with the change in BMD, premenopausal women lost bone more rapidly than postmenopausal patients [mean (SD) $-1 \cdot 8(3 \cdot 6)$ and $-2 \cdot 8$ $(6 \cdot 2) v-0 \cdot 1(4 \cdot 3)$ and $-2 \cdot 1(6)$ (NS) spine and femoral neck respectively]. This was despite crosslink excretion rates being elevated in the postmenopausal women. The ratio to pyridinoline to deoxypyridinoline showed a significant difference between postmenopausal patients and controls (table 3). Eight patients

Table 3 Pyridinoline/deoxypyridinoline ratios of patient groups compared with controls

\begin{tabular}{llll}
\hline & Number & $\begin{array}{l}\text { Pyridinoline/ } \\
\text { deoxypyridinoline } \\
\text { ratio, mean }(S D)\end{array}$ & p Value \\
\hline Controls & 56 & $4 \cdot 72(1.4)$ & \\
Patients (all) & 62 & $4 \cdot 28(1.2)$ & NS \\
Men & 20 & $4 \cdot 60(1.0)$ & NS \\
$\begin{array}{l}\text { Premenopausal } \\
\quad \text { women }\end{array}$ & 14 & $4 \cdot 50(1 \cdot 8)$ & NS \\
$\begin{array}{l}\text { Postmenopausal } \\
\quad \text { women }\end{array}$ & 28 & $3.96(1.0)$ & $\mathrm{p}<0.001$ \\
\hline
\end{tabular}

NS = Not significant. 
Table 4 Effect of disease activity on BMD and crosslink excretion, mean $S D$

\begin{tabular}{|c|c|c|c|}
\hline & $C R P<20$ & p Value & $C R P>20$ \\
\hline \multicolumn{4}{|c|}{ BMD $\%$ change over 1 year } \\
\hline Spine & $+1 \cdot 3(3 \cdot 9)$ & 0.001 & $-2 \cdot 1(3 \cdot 7)$ \\
\hline Femoral neck & $+0 \cdot 6(5 \cdot 1)$ & 0.003 & $-3 \cdot 5(4 \cdot 8)$ \\
\hline \multicolumn{4}{|c|}{8 hour urinary excretion rates } \\
\hline $\begin{array}{l}\text { Pyridinoline } \\
\mathrm{nmol} / 8 \text { hour }\end{array}$ & $220(103)$ & $0 \cdot 02$ & $290(18)$ \\
\hline $\begin{array}{l}\text { Deoxypyridinoline } \\
\text { nmol/8 hour }\end{array}$ & $62(30)$ & NS & $68(39)$ \\
\hline
\end{tabular}

$\mathrm{BMD}=$ Bone material density $\mathrm{CRP}=\mathrm{C}$ reactive protein.

took oral steroids, two each in the pre- and postmenopausal groups and four men. Only two patients took HRT.

To assess the role of disability and disease activity in determining the rate of bone loss, the patients were sub-divided on the basis of their mean acute phase and functional ability scores. Active disease was taken as mean CRP $\geqslant 20$ $\mathrm{mg} / \mathrm{dl}$ or ESR $>30$ and significant disability as $\mathrm{HAQ}>8$ and $\mathrm{FG}>2$. These were arbitrarily assigned before any statistical analysis. Disease activity, as assessed by mean CRP, was significantly associated with bone loss and increased pyridinoline excretion (table 4). Analysis using ESR produced results of similar significance. The HAQ score, as a measure of disability, had no significant effect on either bone loss or crosslink excretion (data not shown). Using an analysis of covariance for all factors confirmed the association of disease activity with crosslink excretion rates and bone loss. Although there was no correlation between deoxypyridinoline excretion and changes at the femoral neck or lumbar spine, there was an association between BMD loss at the femoral neck and pyridinoline excretion $(\mathrm{p}<0 \cdot 01)$.

\section{Discussion}

This study demonstrated that urinary pyridinoline excretion was increased in patients with RA compared with controls and was significantly associated with disease activity, consistent with previous studies. ${ }^{19} 20$ For deoxypyridinoline (the more bone specific crosslink), levels did not correlate with activity in line with previous studies. ${ }^{19} 20$ Previous studies examining patients in the chronic phase of RA cross sectionally have demonstrated an association between BMD loss and disability. ${ }^{9} 142829$ In our study this association was not found despite using HAQ as a more sensitive index of functional loss. There was, however, a significant correlation between BMD loss and CRP with similar findings for ESR (table 4). The separation between disease activity and disability scores in these patients was possibly a consequence of the minimal joint damage of patients studied at this stage of their disease.

Substantial axial bone loss occurring in premenopausal women was observed with losses of greater than $10 \%$ over one year in some nonsteroid treated patients. Bone histomorphometry in RA patients has shown that trabecular thinning occurs in premenopausal women, and also men, whereas trabecular breaks can occur in postmenopausal women. ${ }^{30}$ The former may be reversible but the latter are not. As BMD loss is associated with CRP, this might suggest that early and complete suppression of the acute phase response is important in these patients. Longitudinal data will be required to properly address this question.

DXA scans remain the gold standard for measuring bone loss. Their inherent disadvantage is that they are long term measures of outcome that are insensitive to short term change. There is a clinical need for markers which are capable of determining changes in bone turnover, allowing rapid assessment of response to therapy. In osteoporotic patients, excretion of deoxypyridinoline may have such a role and has been found to correlate with radiostrontium measurements of bone resorption. ${ }^{22}{ }^{23} \mathrm{We}$, however, found no association between the excretion of this crosslink and BMD change over one year, whereas pyridinoline excretion was significantly associated with BMD loss at the femoral neck $(p<0.01)$. It is possible therefore that the excretion of pyridinoline from intra articular, juxta articular and axial sites explains this correlation with bone loss in these patients with early RA.

This study has shown that a single estimation of urinary pyridinoline excretion in patients with early RA correlated significantly with bone loss at the femoral neck. This could become a useful predictive test, especially as there is now evidence that a spot early morning urine specimen may provide the same information. ${ }^{31}$

This work was supported by the Arthritis and Rheumatism Council. We thank Heather Smith for typing the manuscripts and Miss Wendy Hopkins, $\mathrm{Mr}$ Colin Reeves, and $\mathrm{Mr} J$ Winkles, for their help with laboratory sample storage and for serial analysis of RF and CRP on these specimens.

1 Woolf A D. Osteoporosis in rheumatoid arthritis - the clinical viewpoint. $B r \mathcal{F}$ Rheumatol 1992; 30: 82.

2 Bywaters E G L. The early radiological signs of rheumatoid arthritis. Bull Rheum Dis 1960; 11: 231-4

3 Arnett F C, Edworthy S M, Block D A, et al. The American Rheumatism Assciation 1987 revised criteria for the classification of rheumatoid arthritis. Arthritis Rheum 1988; 31: 315-24.

4 McConkey B, Fraser G M, Bligh A S. Transparent skin and osteoporosis. Ann Rheum Dis 1965; 24: 219-23.

5 Saville P D, Kharmosh O. Osteoporosis of rheumatoid arthritis: influence of age, sex and corticosteroids. Arthritis arthritis: influence of age,

6 Bjelle $\mathrm{H}$ O, Nilsson B E. Osteoporosis in rheumatoid arthritis. Calcified Tissue Research 1970; 5: 327-32.

7 Kennedy A C, Smith D A, Buchanan W W, Anderson J B Jasani $\mathrm{M} \mathrm{K}$. Bone loss in patients with rheumatoid Jasani M K. Bone loss in patients with
arthritis. Scand $\mathcal{F}$ Rheumatol 1975; 4: 73-9.

8 Reid D M, Kennedy N S J, Smith M A, Tothill P, Nuki G Total body calcium in rheumatoid arthritis: effects of disease activity and corticosteroid treatment. $B M \mathcal{F} 1982$ 285: $330-2$.

9 Sambrook P N, Eisman J A, Champion G D, Yeates M G Pocock N A, Eberl S. Determinants of axial bone loss in rheumatoid arthritis. Arthritis Rheum 1987; 30: 721-8.

10 Hooyman J R, Melton L J, Nelson A M, O'Fallon W M, Riggs B L. Fractures after rheumatoid arthritis. A population based study. Arthritis Rheum 1985; 27: 1353-61.

11 Verstraeten A, Dequeker J. Vertebral and peripheral bone mineral content and fracture incidence in postmenopausal patients with rheumatoid arthritis: effect of low dose corticosteroids. Ann Rheum Dis 1986; 45
$852-7$. Osteoporosis. Br f Rheumatol 1991; 30: 135-7.

13 Royal College of Physicians of London. Fractured neck of femur: prevention and management. London: Royal College of Physicians 1989. 
14 Virtama P, Helela T, Kalliomaki J L. Osteoporosis in rheumatoid arthritis. Acta Rheum Scand 1968; 14:

15 Als O S, Christiansen C, Hellensen C. Prevalence of decreased bone mass in rheumatoid arthritis. Relation to anti-inflammatory treatment. Clin Rheumatol 1984; 3 201-8

16 Sambrook P N, Ansell B M, Foster S, Gumpel J M, Hesp $\mathrm{R}$, Reeve J. Bone turnover in early rheumatoid arthritis 2. Longitudinal bone density studies. Ann Rheum Dis 1985; 44: 580-4.

17 Lilley J, Walters B G, Health D A, Drolc Z. In vivo and in vitro precision for bone density measured by dual-energy $\mathrm{x}$-ray absorbtion. Osteoporosis Int 1991; 1: 141-6.

18 Robins S P, Stewart P, Astbury C, Bird H A. Measurement of the crosslinking compound pyridinoline in urine as an index of collagen degradation in joint disease. Ann Rheum Dis 1986; 45: 969-73.

19 Seibel M J, Duncan A, Robins S P. Urinary hydroxypyridinium crosslinks provide indices of cartilage and bone involvement in arthritic diseases. $\mathcal{F}$ Rheumatol 1989

20 Black D, Marabani M, Sturrock R D, Robins S P. Urinary excretion of the hydroxypyridinium crosslinks of collagen in patients with rheumatoid arthritis. Ann Rheum Dis 1989; 48: $641-4$.

21 Eyre D R, Koob T L, Van Ness K P. Quantitation of hydroxypyridinium crosslinks by high-performance liquid chromatography. Anal Biochem 1984; 137: 380-8.

22 Colwell A, Eastell R, Assiri A M A, Russell R G G. Effect of diet on deoxypyridinoline excretion. In: Christiansen C, Overgaard K, eds. Osteoporosis 1990. Copenhagen: Osteopress, 1990: 590-1.

23 Black D, Duncan A, Robins S P. Quantitative analysis of the pyridinium crosslinks of collagen in urine using ionpaired reverse-phase high-performance liquid paired reverse-phase high-performance liquid

24 Eastell R, Hampton L, Colwell A, et al. Urinary collagen crosslinks are highly correlated with radioisotopic measurements of bone resorbtion. In: Christiansen C Overgaard K, eds. Osteoporosis 1990. Copenhagen Osteopress, 1990: 469-70.

25 Fries J F. The dimensions of health outcomes: the Health Assessment Questionnaire. 7 Rheumatol 1982; 74: 786-93.

26 Steinbroker O, Traeger C H, Batterman E C. Therapeutic criteria in rheumatoid arthritis. $\mathcal{F} A M A$ 1949; 140: 659-62.

27 Eastell R, Simmons P S, Colwell A, et al. Nyctohemeral changes in bone turnover assessed by serum bone Glaprotein concentration and urinary deoxypyridinoline excretion: effects of growth and ageing. Clinical Science

28 Hancock D A, Asiedu-offei S, Atkinson P J, Reed G W Wright V. Femoral bone mass in patients with rheumatoid arthritis and osteoporosis. Rheum and Rehabil 1978; 17: $65-71$.

29 Mararo M, Triceri A, Piane D, et al. Generalised osteoporosis in non-steroid treated rheumatoid arthritis. Rheum Int 1991; 11: 73-6.

30 Compston J E, Crawley E O, Evans C, O'Sullivan M M. Spinal trabecular bone mineral content in patients with non-steroid treated rheumatoid arthritis. Ann Rheum Dis 1988; 47: 660-4.

31 McLaren A M, Isdale A $\mathrm{H}$, Whiting $\mathrm{P} \mathrm{H}$, Peace $\mathrm{H}$, Bird H A, Robins S P. Physiological variation in the urinary excretion of pyridinoline crosslinks of collagen. $\mathrm{Br} f$ Rheumatol 1993; 32: 307-12. 